\title{
28 Research Square \\ The global prevalence of dry eye disease and its association with economy: a systematic review
}

\author{
Yu Wan \\ Peking University Third Hospital \\ Mingzhou Zhang \\ Peking University Third Hospital \\ Xuemin Li ( $\sim$ 13911254862@163.com ) \\ Peking University Third Hospital
}

\section{Research article}

Keywords: Dry eye disease; Prevalence; Epidemiology; Economy; Gross domestic product per capita; Gross national income per capita

Posted Date: July 4th, 2019

DOl: https://doi.org/10.21203/rs.2.10986/v1

License: @ (i) This work is licensed under a Creative Commons Attribution 4.0 International License. Read Full License 


\section{Abstract}

Objective To investigate the relationship between the economy and the prevalence of dry eye disease (DED) worldwide. Methods Literature search on PubMed, Cochrane and Embase database was conducted to identify eligible records published from January 2008 to December 2018. Gross domestic product (GDP) per capita and gross national income (GNI) per capita was chosen to evaluate national economic status. Pearson coefficient, linear regression, and t test were performed in the statistical analyses. Results 32 population-based surveys conducted in 17 countries were included, with a total of 184255 subjects. The pooled mean prevalence of DED was $14.6 \%$, and female individuals presented a higher prevalence than males $(16.8 \%$ versus $11.5 \%, P<0.001)$. The prevalence of DED was negatively correlated with GNI per capita $(P<0.001, r=0.603)$ and GDP per capita $(P<0.001, r=0.600)$. Grouped by World Bank Income classifications, the prevalence of DED progressively declined with an increase in economic level from lower-middle-income countries (LMICs) to high-income countries (HICs). Remarkable difference was found between the prevalence of DED in LMICs and that in HICs $(P<0.001)$. Conclusions This study suggested a correlation between the economy and the prevalence of DED worldwide. These findings may provide valuable information on the global prevalence of DED from a distinctive epidemiologic perspective.

\section{Background}

Dry eye disease (DED) is a highly prevalent ocular surface disease across the world, and has become one of the leading causes for visits to the oculist [1]. It is defined as a multifactorial disease of the ocular surface characterized by a loss of homeostasis of the tear film, and accompanied by ocular symptoms, in which tear film instability and hyperosmolarity, ocular surface inflammation and damage, and neurosensory abnormalities play etiological roles [2]. Symptoms of DED include eye irritation, dryness, stinging, ocular fatigue, and fluctuating visual disturbances $[3,4]$. These symptoms can lead to significant impairments in patients' daily life and social activities [5, 6]. Besides, DED poses a substantial economic burden to the society owing to associated health care costs and loss of job productivity $[7,8]$. All of these make DED an important public health problem.

Estimates of DED prevalence in the general population varied greatly between studies, ranging from $5 \%$ to $50 \%[9,10]$. The large variation not only comes from the heterogeneous characteristics of investigated population, but also stems from the disparities of diagnostic criteria and evaluation methods [11]. Despite the diverse diagnostic procedure of DED, several crucial risk factors have been recognized [12, 13]. However, current studies reporting risk factors for DED have mainly focused on demographic and behavioral factors, for example, female sex, advanced age, contact lens wear, and visual display terminal usage [14]. Economic status is one of the crucial social determinants of health, and as such, it has a nonnegligible influence on the risk of numerous health problems [15]. It was reported that economic divergences could cause differences in material conditions, access to medical-care services, as well as health awareness and attitudes, and thus affect health status of the individuals $[16,17]$. Nevertheless, to our knowledge, no wide-ranging studies have been conducted to prove whether the prevalence of DED 
correlated with economic status. Therefore, we carried out the present meta-analysis of large populationbased surveys performed worldwide, aiming to explore the association between economic level and DED prevalence in a worldwide range. It is believed that this study will offer a novel epidemiologic perspective on the global prevalence of DED.

\section{Methods}

\section{Search strategy}

This study was performed and reported according to the preferred reporting items for systemic reviews and meta-analyses (PRISMA) guidelines for systematic reviews and meta-analyses [18]. We searched PubMed, Cochrane and Embase databases to identify eligible studies published from January 2008 to December 2018. The search terms used were (dry eye syndrome, OR dry eye, OR meibomian gland dysfunction, OR MGD, OR keratoconjunctivitis sicca, NOT Sjögren syndrome) AND (prevalence OR incidence OR epidemiology OR morbidity). We also reviewed bibliographies of all the included articles and relevant reviews to identify other potentially pertinent studies.

\section{Study Selection}

Eligibility for inclusion were as follows: primary, original research studies reporting the prevalence of dry eye symptoms and/or signs, and the study population is representative of the general population, with a minimum of 500 subjects. Non-original literature (e.g., review, comment, letter) and repeated publications were excluded. In case the studied population overlapped between publications, we only selected the studies with the largest sample size.

\section{Data extraction}

The data of each study, including first author, publication year, survey year(s), country, sample size, age range, sex ratio, diagnosis criteria, overall prevalence with corresponding 95\% confidence intervals (95\% $\mathrm{Cl}$ ), and gender-specific prevalence, were extracted and stored in a Microsoft Excel spreadsheet. The Strengthening the Reporting of Observational Studies in Epidemiology (STROBE) guideline was used to evaluate the qualities of the included studies [19].

\section{Economic status assessment}

The economic status of each country was assessed by gross domestic product (GDP) per capita and gross national income (GNI) per capita of the survey year, which could be retrieved from the Web site of World Bank [20]. In case the duration of investigation exceeded one year, the middle year of the study period was taken as the survey year. For articles failed to offer the precise investigated time, the survey year was estimated as 3 years (mean survey duration calculated according to the available data) before the publication year. Based on the 2019 World Bank's classification, the national economic level was also 
stratified into four groupings, including low-income countries (LICs), lower-middle-income countries (LMICs), upper-middle-income countries (UMICs) and high-income countries (HICs) [21].

\section{Statistical analysis}

Statistical analysis was performed using SPSS 20.0 (IBM, Chicago, IL, United States) and Prism 6.0 (GraphPad, San Diego, CA, United States). Association between DED prevalence and national economic status was calculated by Pearson correlation. Linear regression was conducted if available. T test was used to evaluate differences of prevalence between two related samples. $P<0.05$ was considered statistically significant.

\section{Results}

As shown in Figure 1, 2746 records were obtained from the literature search: 966 in PubMed, 1156 in Cochrane and 624 in Embase. From those, 58 articles that fulfilled the inclusion criteria were identified. After removing the studies which were carried out in the same population or special population, 32 surveys were included in the meta-analysis finally.

\section{Characteristics of included studies}

The characteristics of included studies are listed in Table 1 and Supplementary Table.

The retained studies were conducted in 17 countries spread across five continents around the world. The data of Oceania or Antarctica was lack because no studies conducted in this two continents was found to fulfilled the eligibility criteria, e.g., a minimum sample size of 500 subjects in general population. As for WHO regions, this study covered all the six regions, with WPRO contributing the largest number of studies. In total, 184255 individuals were included in this literature review. Population sizes ranged from 510 to 73211 subjects. The minimum age of participants studied was 5.5 years and the maximum was 96 years.

\section{Diagnosis criteria for dry eye disease}

The diagnosis criteria for DED differed among studies and could be grouped into three categories: subjective symptoms, objective signs, and combination of the two (Supplementary Table). 29 studies reported the prevalence of DED with symptoms as a diagnosis criterion [14, 22-24, 26-31, 33-36, 38-40, 4250]. To be specific, the subjective assessment included Ocular Index Disease Index (OSDI) questionnaire, number and frequency of dry eye symptoms, with or without the history of dry eye diagnosed by a clinician. 11 studies presented the prevalence of DED diagnosed using clinical signs only [23, 24, 26-29, $32,33,43,50,51]$. Some studies used a single clinical sign and others a combination of tear stability, tear production and ocular surface damage signs. Marked heterogeneity was found between studies due to the difference of selected clinical tests as well as the variation in cut-off values of dry eye diagnosis. In addition, 6 studies defined DED by combination of dry eye symptoms and signs, and described the corresponding prevalence $[29,32,33,43,52,53]$. Estimates of the DED prevalence from all eligible 
studies, stratified by diagnostic criteria, are tabulated and summarized in Table 1 and Supplementary Table.

\section{Gender and regional prevalence of dry eye disease}

The pooled prevalence of DED was $14.6 \%$ in overall population (Table 2 ). The pooled prevalence rate in female individuals was significantly higher than that in males $(16.8 \%$ versus $11.5 \%)(P<0.001)$ (Figure $2 \mathrm{~A}$ and Table 2). Among the WHO regions, AFRO region had the highest prevalence (44.3\%), followed by SEARO (31.3\%), EMRO (25.0\%), WPRO (24.2\%) and EURO (16.2\%). AMRO had the lowest prevalence of $7.6 \%$ (Figure 2B and Table 2). No significant difference was found in prevalence rate between regions. The prevalence of DED in Asia was the highest (27.1\%), while it was $16.4 \%$ in Europe, $14.2 \%$ in Africa and $12.8 \%$ in South America. North America had the lowest prevalence of $7.4 \%$ (Figure $2 \mathrm{C}$ and Table 2). No significant difference was found in prevalence rate between continents.

\section{Correlation between prevalence of DED and economic status}

Grouped according to the World Bank Income classifications, the prevalence of DED progressively declined with an increase in economic level from LMICs to HICs (Figure 2D and Table 2). Significant difference was found between the prevalence of DED in LMICs and that in HICs $(P<0.001)$. The pooled prevalence of DED was significantly correlated with GNI per capita according to Pearson correlation and linear regression analysis $(P<0.001, r=0.603)$ (Figure $3 A)$. Similarly, notable correlation was found between the prevalence of DED and GDP per capita $(P<0.001, r=0.600)$ (Figure 3B).

\section{Discussion}

To our knowledge, this is the first time to explore the association between DED prevalence and economic level worldwide. Our findings show that there are remarkable differences in the prevalence of DED in different countries of the world, and the prevalence of DED was inversely correlated with economic level judged by GNI per capita or GDP per capita.

As was previously reported, the prevalence of DED in different studies varied with the operational methodology and diagnostic definition of dry eye used (subjective symptoms and/or objective findings). Among the included 32 surveys in our study, 29 surveys reported the prevalence of DED diagnosed by symptoms, accounting for a large proportion. This is mainly because dry eye is generally regarded as a symptomatic disease, and symptom questionnaires are among the most repeatable and commonly used diagnostic tools at the present time. 11 surveys used one or more clinical signs to as an indicator of dry eye, such as corneal staining, tear production and tear instability. However, significant heterogeneity was perceived between studies due to the inconformity of cut-off values and poor repeatability of these tests. Only 6 studies reported the prevalence of DED on a combination of symptoms and signs, very different criteria were also noted in each of the studies. 
Based on the findings discussed above, it is challenging to do comparisons between studies in consideration of the heterogeneity in disease definitions [54]. In previous studies, it has been detected that the prevalence of DED diagnosed by clinical examinations does not correspond to that based on subjective symptoms alone $[55,56]$. Moreover, due to the lack of a well-standardized and common-used diagnostic criteria for clinical tests, the prevalence of signs showed greater variability than symptoms [57]. Therefore, to diminish part of the bias stemmed from the diagnostic methodology, we chose the 29 studies using symptoms as a diagnostic criterion for further analysis.

Our study revealed a pooled prevalence rate of DED at $14.6 \%$ in a total population of 184255 individuals, ranging from $9.5 \%$ to $87.5 \%$. With respect to gender, we found that the female prevalence of DED was significantly higher than that of male, which was consistent with the previous studies [58]. However, other risk factors for DED (e.g., age, computer use, contact lens wear, and systemic or ocular medications) were precluded in this study due to the insufficiency of information supplied. As for geographic regions, we failed to detect any significant difference in prevalence rate between continents or WHO regions. The heterogeneity of diagnostic criteria discussed above was one possible reason. Another hypothetical explanation was that the difference may be eliminated as a result of interactions by several geographic related factors (e.g., ethnicity, climate, humidity and altitude).

In this study, a negative correlation was found between the prevalence of DED and the economic indicators of the surveyed countries according to Pearson correlation and linear regression analysis. When classifying the countries by GNI per capita, it was also noticed that the prevalence of DED decreased along with the progressively higher economic level from LMICs to HICs. So far, there was no definite explanation for the correlation observed between the prevalence of DED and the national economic level. Previous social-economic analysis of DED merely focused more on medical expense and economic burden resulted by DED $[59,60]$. However, according to studies on other chronic disease, it has also been found an increasing trend in the prevalence of chronic diseases in lower income group [61, 62]. The plausible explanation for this phenomenon is that individuals in lower-income countries tended to have less access to health-care services, lower understanding of the disease status, and more unhealthy lifestyle behaviors $[63,64]$. It has been reported that individuals from lower economic groups, particularly those who are confronted with poverty and many other socioeconomic difficulties, have impaired medical access system and fewer referrals for specialist care $[16,65]$. Economic status might also influence health awareness and practices in the general public. There is evidence that individuals from high-income countries tended to have better awareness of damaged health and higher prevalence of healthy lifestyle behaviors [66]. All these discussed above may contribute to the disparity of DED prevalence between the lower-income countries and higher-income countries.

The strength of this study is as follows. Firstly, it is the first time to use GNI per capita and GDP per capita, as excellent parameters for economic level, to investigate the relationship between DED prevalence and economic status. Secondly, considering the diversity of diagnostic methodology, we distinguished the patients diagnosed by subjective symptoms from those by objective signs only or 
combination of the two, and separately analyzed the influence of economic level on DED. Finally, the included studies were based on the general population for more generalizable results.

The limitations of our study should also be addressed. First of all, the data of DED incidence was unavailable for many countries, especially those with low economic levels, which limited the accuracy and reliability of our findings. Besides, despite our best efforts to minimize variations caused by diagnostic criteria, significant heterogeneity was still observed among the included studies. Lastly, there are several other important factors that should have been incorporated into the statistics, such as environmental status, educational level, visual display usage, ethnic and genetic risk factors, etc. However, the studies that we retained rarely illustrated these crucial covariates. The complex interaction between the incidence of DED and these predictors still needs deeper exploration in further study.

\section{Conclusions}

In conclusion, this study exhibited remarkable differences in DED prevalence in different countries worldwide, and revealed a negative correlation between the prevalence of DED and economic status. These findings may offer a novel epidemiological viewpoint on the global conditions of DED.

\section{Abbreviations}

DED: dry eye disease; GDP: gross domestic product; GNI: gross national income; Cl: confidence intervals; PRISMA: preferred reporting items for systemic reviews and meta-analyses; STROBE: strengthening the reporting of observational studies in epidemiology; MGD: meibomian gland dysfunction; LICs: lowincome countries; LMICs: lower-middle-income countries; UMICs: upper-middle-income countries; HICs: high-income countries; OSDI: Ocular Index Disease Index; AFRO: African Region; SEARO: East Asia and Pacific; EURO: European Region; EMRO: Eastern Mediterranean Region; WPRO: Western Pacific Region.

\section{Declarations}

\section{Ethics approval and consent to participate}

Not applicable.

\section{Consent for publication}

Not applicable. 
Not applicable.

\section{Competing interests}

The authors declare that they have no competing interests.

\section{Funding}

This study was supported by Capital's Funds for Health Improvement and Research (Grant Number: 20182-4093). The funders had no role in study design, data collection, analysis and interpretation and writing the manuscript.

\section{Authors' contributions}

All authors were involved in the conception and design of this study. YW and MZ conducted the search, screened all abstracts and full-text papers for eligibility and performed quality assessment and dataextraction. XL oversaw the study, and supervised the findings of this work. YW wrote the drafts of the manuscript and all other authors critically revised the different versions of the manuscript. All authors read and approved the final manuscript.

\section{Acknowledgments}

Not applicable.

\section{Authors' Information}

Peking University Third Hospital, Peking University Eye Centre, 49 North Garden Road, Haidian District, Beijing 100191, China.

\section{References}

[1] X. Zhang, V.J. M, Y. Qu, X. He, S. Ou, J. Bu, C. Jia, J. Wang, H. Wu, Z. Liu, W. Li, Dry Eye Management: Targeting the Ocular Surface Microenvironment, International journal of molecular sciences, 18 (2017). 
[2] J.P. Craig, K.K. Nichols, E.K. Akpek, B. Caffery, H.S. Dua, C.K. Joo, Z. Liu, J.D. Nelson, J.J. Nichols, K. Tsubota, F. Stapleton, TFOS DEWS II Definition and Classification Report, The ocular surface, 15 (2017) 276-283.

[3] J. Vehof, N. Sillevis Smitt-Kamminga, S.A. Nibourg, C.J. Hammond, Predictors of Discordance between Symptoms and Signs in Dry Eye Disease, Ophthalmology, 124 (2017) 280-286.

[4] J. Vehof, N. Sillevis Smitt-Kamminga, D. Kozareva, S.A. Nibourg, C.J. Hammond, Clinical Characteristics of Dry Eye Patients With Chronic Pain Syndromes, American journal of ophthalmology, 162 (2016) 59-65.e52.

[5] M. Li, L. Gong, W.J. Chapin, M. Zhu, Assessment of vision-related quality of life in dry eye patients, Investigative ophthalmology \& visual science, 53 (2012) 5722-5727.

[6] Q. Le, L. Ge, M. Li, L. Wu, J. Xu, J. Hong, L. Gong, Comparison on the vision-related quality of life between outpatients and general population with dry eye syndrome, Acta ophthalmologica, 92 (2014) e124-132.

[7] M. McDonald, D.A. Patel, M.S. Keith, S.J. Snedecor, Economic and Humanistic Burden of Dry Eye Disease in Europe, North America, and Asia: A Systematic Literature Review, The ocular surface, 14 (2016) 144-167.

[8] J.P. Clegg, J.F. Guest, A. Lehman, A.F. Smith, The annual cost of dry eye syndrome in France, Germany, Italy, Spain, Sweden and the United Kingdom among patients managed by ophthalmologists, Ophthalmic epidemiology, 13 (2006) 263-274.

[9] F. Stapleton, M. Alves, V.Y. Bunya, I. Jalbert, K. Lekhanont, F. Malet, K.S. Na, D. Schaumberg, M. Uchino, J. Vehof, E. Viso, S. Vitale, L. Jones, TFOS DEWS II Epidemiology Report, The ocular surface, 15 (2017) 334-365.

[10] P. Rao Donthineni, P. Kammari, S.S. Shanbhag, V. Singh, A.V. Das, S. Basu, Incidence, demographics, types and risk factors of dry eye disease in India: Electronic medical records driven big data analytics report I, The ocular surface, (2019).

[11] J.S. Wolffsohn, R. Arita, R. Chalmers, A. Djalilian, M. Dogru, K. Dumbleton, P.K. Gupta, P. Karpecki, S. Lazreg, H. Pult, B.D. Sullivan, A. Tomlinson, L. Tong, E. Villani, K.C. Yoon, L. Jones, J.P. Craig, TFOS DEWS II Diagnostic Methodology report, The ocular surface, 15 (2017) 539-574.

[12] P. Song, W. Xia, M. Wang, X. Chang, J. Wang, S. Jin, J. Wang, W. Wei, I. Rudan, Variations of dry eye disease prevalence by age, sex and geographic characteristics in China: a systematic review and metaanalysis, Journal of global health, 8 (2018) 020503.

[13] The epidemiology of dry eye disease: report of the Epidemiology Subcommittee of the International Dry Eye WorkShop (2007), The ocular surface, 5 (2007) 93-107. 
[14] M. Uchino, Y. Nishiwaki, T. Michikawa, K. Shirakawa, E. Kuwahara, M. Yamada, M. Dogru, D.A. Schaumberg, T. Kawakita, T. Takebayashi, K. Tsubota, Prevalence and risk factors of dry eye disease in Japan: Koumi study, Ophthalmology, 118 (2011) 2361-2367.

[15] Y. Bird, M. Lemstra, M. Rogers, The effects of household income distribution on stroke prevalence and its risk factors of high blood pressure and smoking: a cross-sectional study in Saskatchewan, Canada, Perspectives in public health, 137 (2017) 114-121.

[16] S. Kim, B. Lee, M. Park, S. Oh, H.J. Chin, H. Koo, Prevalence of chronic disease and its controlled status according to income level, Medicine, 95 (2016) e5286.

[17] H. Kato, K. Tanaka, K. Shimizu, C. Nagata, S. Furukawa, M. Arakawa, Y. Miyake, Parental occupations, educational levels, and income and prevalence of dental caries in 3-year-old Japanese children, Environmental health and preventive medicine, 22 (2017) 80.

[18] A. Liberati, D.G. Altman, J. Tetzlaff, C. Mulrow, P.C. Gotzsche, J.P. loannidis, M. Clarke, P.J. Devereaux, J. Kleijnen, D. Moher, The PRISMA statement for reporting systematic reviews and meta-analyses of studies that evaluate health care interventions: explanation and elaboration, Ann Intern Med, 151 (2009) W65-94.

[19] J.P. Vandenbroucke, E. von Elm, D.G. Altman, P.C. Gotzsche, C.D. Mulrow, S.J. Pocock, C. Poole, J.J. Schlesselman, M. Egger, Strengthening the Reporting of Observational Studies in Epidemiology (STROBE): explanation and elaboration, Ann Intern Med, 147 (2007) W163-194.

[20] World Bank. Countries and Economies.

[21] World Bank Country and Lending Groups.

[22] J.S. Castro, I.B. Selegatto, R.S. Castro, E.C.M. Miranda, J.P.C. de Vasconcelos, K.M. de Carvalho, C.E.L. Arieta, M. Alves, Prevalence and Risk Factors of self-reported dry eye in Brazil using a short symptom questionnaire, Sci Rep, 8 (2018) 2076.

[23] R. Hua, K. Yao, Y. Hu, L. Chen, Discrepancy between subjectively reported symptoms and objectively measured clinical findings in dry eye: a population based analysis, BMJ open, 4 (2014) e005296.

[24] P. Lu, X. Chen, X. Liu, L. Yu, Y. Kang, Q. Xie, L. Ke, X. Wei, Dry eye syndrome in elderly Tibetans at high altitude: a population-based study in China, Cornea, 27 (2008) 545-551.

[25] Y. Zhang, H. Chen, X. Wu, Prevalence and risk factors associated with dry eye syndrome among senior high school students in a county of Shandong Province, China, Ophthalmic epidemiology, 19 (2012) 226-230.

[26] Y. Jie, L. Xu, Y.Y. Wu, J.B. Jonas, Prevalence of dry eye among adult Chinese in the Beijing Eye Study, Eye (London, England), 23 (2009) 688-693. 
[27] B. Guo, P. Lu, X. Chen, W. Zhang, R. Chen, Prevalence of dry eye disease in Mongolians at high altitude in China: the Henan eye study, Ophthalmic epidemiology, 17 (2010) 234-241.

[28] F. Malet, M. Le Goff, J. Colin, C. Schweitzer, M.N. Delyfer, J.F. Korobelnik, M.B. Rougier, T. Radeau, J.F. Dartigues, C. Delcourt, Dry eye disease in French elderly subjects: the Alienor Study, Acta ophthalmologica, 92 (2014) e429-436.

[29] A. Ferrero, S. Alassane, C. Binquet, L. Bretillon, N. Acar, L. Arnould, A. Muselier-Mathieu, C. Delcourt, A.M. Bron, C. Creuzot-Garcher, Dry eye disease in the elderly in a French population-based study (the Montrachet study: Maculopathy, Optic Nerve, nuTRition, neurovAsCular and HEarT diseases): Prevalence and associated factors, The ocular surface, 16 (2018) 112-119.

[30] K. Asiedu, S. Kyei, F. Boampong, S. Ocansey, Symptomatic Dry Eye and Its Associated Factors: A Study of University Undergraduate Students in Ghana, Eye \& contact lens, 43 (2017) 262-266.

[31] J.S. Titiyal, R.C. Falera, M. Kaur, V. Sharma, N. Sharma, Prevalence and risk factors of dry eye disease in North India: Ocular surface disease index-based cross-sectional hospital study, Indian Journal of Ophthalmology, 66 (2018) 207-211.

[32] H. Hashemi, M. Khabazkhoob, A. Kheirkhah, M.H. Emamian, S. Mehravaran, M. Shariati, A. Fotouhi, Prevalence of dry eye syndrome in an adult population, Clinical \& experimental ophthalmology, 42 (2014) 242-248.

[33] S. Amano, K. Inoue, Clinic-Based Study on Meibomian Gland Dysfunction in Japan, Investigative ophthalmology \& visual science, 58 (2017) 1283-1287.

[34] M. Uchino, M. Dogru, Y. Uchino, K. Fukagawa, S. Shimmura, T. Takebayashi, D.A. Schaumberg, K. Tsubota, Japan Ministry of Health study on prevalence of dry eye disease among Japanese high school students, American journal of ophthalmology, 146 (2008) 925-929.e922.

[35] M.M. Bakkar, W.A. Shihadeh, M.F. Haddad, Y.S. Khader, Epidemiology of symptoms of dry eye disease (DED) in Jordan: A cross-sectional non-clinical population-based study, Contact lens \& anterior eye : the journal of the British Contact Lens Association, 39 (2016) 197-202.

[36] S.B. Han, J.Y. Hyon, S.J. Woo, J.J. Lee, T.H. Kim, K.W. Kim, Prevalence of dry eye disease in an elderly Korean population, Archives of ophthalmology (Chicago, III. : 1960), 129 (2011) 633-638.

[37] W. Lee, S.S. Lim, J.U. Won, J. Roh, J.H. Lee, H. Seok, J.H. Yoon, The association between sleep duration and dry eye syndrome among Korean adults, Sleep medicine, 16 (2015) 1327-1331.

[38] E.O. Graue-Hernandez, J.C. Serna-Ojeda, C. Estrada-Reyes, A. Navas, J. Arrieta-Camacho, A. JimenezCorona, Dry eye symptoms and associated risk factors among adults aged 50 or more years in Central Mexico, Salud publica de Mexico, 60 (2018) 520-527. 
[39] M. Garza-Leon, M. Valencia-Garza, B. Martinez-Leal, P. Villarreal-Pena, H.G. Marcos-Abdala, A.L. Cortez-Guajardo, A. Jasso-Banda, Prevalence of ocular surface disease symptoms and risk factors in group of university students in Monterrey, Mexico, Journal of ophthalmic inflammation and infection, 6 (2016) 44.

[40] A.A. Alshamrani, A.S. Almousa, A.A. Almulhim, A.A. Alafaleq, M.B. Alosaimi, A.M. Alqahtani, A.M. Almulhem, M.A. Alshamrani, A.H. Alhallafi, I.Z. Alqahtani, A.A. Alshehri, Prevalence and Risk Factors of Dry Eye Symptoms in a Saudi Arabian Population, Middle East African journal of ophthalmology, 24 (2017) 67-73.

[41] L. Tong, S.M. Saw, E.L. Lamoureux, J.J. Wang, M. Rosman, D.T. Tan, T.Y. Wong, A questionnairebased assessment of symptoms associated with tear film dysfunction and lid margin disease in an Asian population, Ophthalmic epidemiology, 16 (2009) 31-37.

[42] L.L. Tan, P. Morgan, Z.Q. Cai, R.A. Straughan, Prevalence of and risk factors for symptomatic dry eye disease in Singapore, Clinical \& experimental optometry, 98 (2015) 45-53.

[43] E. Viso, M.T. Rodriguez-Ares, F. Gude, Prevalence of and associated factors for dry eye in a Spanish adult population (the Salnes Eye Study), Ophthalmic epidemiology, 16 (2009) 15-21.

[44] N. Kasetsuwan, S. Gorvanich, S. Erjongmanee, P. Thienprasiddhi, S. Jitapunkul, Prevalence of dry eyes in elderly Thai population (the Romklao eye study), Asian Biomedicine, 6 (2012) 875-882.

[45] J. Vehof, P.G. Hysi, C.J. Hammond, A Metabolome-Wide Study of Dry Eye Disease Reveals Serum Androgens as Biomarkers, Ophthalmology, 124 (2017) 505-511.

[46] J. Vehof, D. Kozareva, P.G. Hysi, C.J. Hammond, Prevalence and risk factors of dry eye disease in a British female cohort, The British journal of ophthalmology, 98 (2014) 1712-1717.

[47] A.J. Paulsen, K.J. Cruickshanks, M.E. Fischer, G.H. Huang, B.E. Klein, R. Klein, D.S. Dalton, Dry eye in the beaver dam offspring study: prevalence, risk factors, and health-related quality of life, American journal of ophthalmology, 157 (2014) 799-806.

[48] K.F. Farrand, M. Fridman, I.O. Stillman, D.A. Schaumberg, Prevalence of Diagnosed Dry Eye Disease in the United States Among Adults Aged 18 Years and Older, American journal of ophthalmology, 182 (2017) 90-98.

[49] D.A. Schaumberg, R. Dana, J.E. Buring, D.A. Sullivan, Prevalence of dry eye disease among US men: estimates from the Physicians' Health Studies, Archives of ophthalmology (Chicago, III. : 1960), 127 (2009) 763-768.

[50] H. Hashemi, H. Rastad, M.H. Emamian, A. Fotouhi, Meibomian gland dysfunction and its determinants in Iranian adults: A population-based study, Contact lens \& anterior eye : the journal of the British Contact Lens Association, 40 (2017) 213-216. 
[51] G.A. Yamamah, A.A. Talaat Abdel Alim, Y.S. Mostafa, R.A. Ahmed, A.M. Mohammed, Prevalence of Visual Impairment and Refractive Errors in Children of South Sinai, Egypt, Ophthalmic epidemiology, 22 (2015) 246-252.

[52] Y.Y. Gong, F. Zhang, J. Zhou, J. Li, G.H. Zhang, J.L. Wang, Z.S. Gu, Prevalence of Dry Eye in Uyghur and Han Ethnic Groups in Western China, Ophthalmic epidemiology, 24 (2017) 181-187.

[53] J.H. Moon, K.W. Kim, N.J. Moon, Smartphone use is a risk factor for pediatric dry eye disease according to region and age: a case control study, BMC ophthalmology, 16 (2016) 188.

[54] V. Valim, V.F. Trevisani, J.M. de Sousa, V.S. Vilela, R. Belfort, Jr., Current Approach to Dry Eye Disease, Clinical reviews in allergy \& immunology, 49 (2015) 288-297.

[55] J.D. Bartlett, M.S. Keith, L. Sudharshan, S.J. Snedecor, Associations between signs and symptoms of dry eye disease: a systematic review, Clinical ophthalmology (Auckland, N.Z.), 9 (2015) 1719-1730.

[56] B.D. Sullivan, L.A. Crews, E.M. Messmer, G.N. Foulks, K.K. Nichols, P. Baenninger, G. Geerling, F. Figueiredo, M.A. Lemp, Correlations between commonly used objective signs and symptoms for the diagnosis of dry eye disease: clinical implications, Acta ophthalmologica, 92 (2014) 161-166.

[57] G. Savini, P. Prabhawasat, T. Kojima, M. Grueterich, E. Espana, E. Goto, The challenge of dry eye diagnosis, Clinical ophthalmology (Auckland, N.Z.), 2 (2008) 31-55.

[58] S. Truong, N. Cole, F. Stapleton, B. Golebiowski, Sex hormones and the dry eye, Clinical \& experimental optometry, 97 (2014) 324-336.

[59] W. Yao, Q. Le, Social-economic analysis of patients with Sjogren's syndrome dry eye in East China: a cross-sectional study, BMC ophthalmology, 18 (2018) 23.

[60] J. Yu, C.V. Asche, C.J. Fairchild, The economic burden of dry eye disease in the United States: a decision tree analysis, Cornea, 30 (2011) 379-387.

[61] Z. Xu, D. Yu, X. Yin, F. Zheng, H. Li, Socioeconomic status is associated with global diabetes prevalence, Oncotarget, 8 (2017) 44434-44439.

[62] J.A. Dalstra, A.E. Kunst, C. Borrell, E. Breeze, E. Cambois, G. Costa, J.J. Geurts, E. Lahelma, H. Van Oyen, N.K. Rasmussen, E. Regidor, T. Spadea, J.P. Mackenbach, Socioeconomic differences in the prevalence of common chronic diseases: an overview of eight European countries, International journal of epidemiology, 34 (2005) 316-326.

[63] M. Asadi-Lari, A. Khosravi, S. Nedjat, M.A. Mansournia, R. Majdzadeh, K. Mohammad, M.R. VaezMahdavi, S. Faghihzadeh, A.A. Haeri Mehrizi, B. Cheraghian, Socioeconomic status and prevalence of self-reported diabetes among adults in Tehran: results from a large population-based cross-sectional study (Urban HEART-2), Journal of endocrinological investigation, 39 (2016) 515-522. 
[64] D.M. Rabi, A.L. Edwards, D.A. Southern, L.W. Svenson, P.M. Sargious, P. Norton, E.T. Larsen, W.A. Ghali, Association of socio-economic status with diabetes prevalence and utilization of diabetes care services, BMC health services research, 6 (2006) 124.

[65] S. Dunlop, P.C. Coyte, W. Mclsaac, Socio-economic status and the utilisation of physicians' services: results from the Canadian National Population Health Survey, Social science \& medicine (1982), 51 (2000) 123-133.

[66] K. Teo, S. Lear, S. Islam, P. Mony, M. Dehghan, W. Li, A. Rosengren, P. Lopez-Jaramillo, R. Diaz, G. Oliveira, M. Miskan, S. Rangarajan, R. Iqbal, R. Ilow, T. Puone, A. Bahonar, S. Gulec, E.A. Darwish, F. Lanas, K. Vijaykumar, O. Rahman, J. Chifamba, Y. Hou, N. Li, S. Yusuf, Prevalence of a healthy lifestyle among individuals with cardiovascular disease in high-, middle- and low-income countries: The Prospective Urban Rural Epidemiology (PURE) study, Jama, 309 (2013) 1613-1621.

\section{Tables}

Table 1. Characteristics of included studies for correlation analyses between the prevalence of DED and GNI per capita/ GDP per capita. 


\begin{tabular}{|c|c|c|c|c|c|c|c|}
\hline $\begin{array}{l}\text { Publication year } \\
\text { (Ref No.) }\end{array}$ & $\begin{array}{l}\text { Survey } \\
\text { year(s) }\end{array}$ & Country & $\begin{array}{l}\text { GNI per } \\
\text { capita }\end{array}$ & $\begin{array}{l}\text { GDP per } \\
\text { capita }\end{array}$ & $\begin{array}{c}\text { Total } \\
\text { Prevalence } \\
(\%)\end{array}$ & $\begin{array}{c}\text { Female } \\
\text { prevalence } \\
(\%)\end{array}$ & $\begin{array}{c}\text { Male } \\
\text { prevalence } \\
(\%)\end{array}$ \\
\hline 2018 [22] & NA & Brazil & 10090 & 8750 & 12.8 & 14.4 & 9.8 \\
\hline 2014 [23] & 2007 & China & 2510 & 2690 & 75.6 & NA & NA \\
\hline 2008 [24] & 2006 & China & 2060 & 2100 & 52.4 & 52.9 & 52.1 \\
\hline 2012 [25] & 2010 & China & 5940 & 4560 & 23.7 & 23.3 & 24.1 \\
\hline 2009 [26] & 2001 & China & 1010 & 1050 & 21 & 23.9 & 17.2 \\
\hline 2010 [27] & 2006 & China & 2060 & 2100 & 50.1 & 50.2 & 49.9 \\
\hline 2014 [28] & $\begin{array}{l}2006- \\
2008\end{array}$ & France & 40230 & 41500 & 21.9 & 27.1 & 13.6 \\
\hline 2018 [29] & $\begin{array}{l}2009- \\
2013\end{array}$ & France & 44190 & 43800 & 34.4 & 39.5 & 25.8 \\
\hline 2016 [30] & NA & Ghana & 1890 & 2400 & 44.3 & 49.8 & 41.6 \\
\hline 2018 [31] & $\begin{array}{l}2014- \\
2016\end{array}$ & India & 1600 & 1610 & 32 & 39.3 & 29.1 \\
\hline 2014 [32] & 2009 & Iran & 5460 & 5620 & 18.3 & 20 & 15.7 \\
\hline 2017 [33] & $\begin{array}{l}2015- \\
2016\end{array}$ & Japan & 38000 & 39000 & 11.2 & 13.3 & 8.3 \\
\hline 2008 [34] & NA & Japan & 38850 & 39400 & 21.6 & 24.4 & 21 \\
\hline 2011 [14] & 2010 & Japan & 43440 & 44500 & 17.4 & 21.6 & 12.5 \\
\hline 2016 [35] & 2015 & Jordan & 3890 & 4100 & 59 & 60.4 & 57.2 \\
\hline 2011 [36] & $\begin{array}{l}2008- \\
2009\end{array}$ & Korea & 21040 & 18300 & 30.3 & 34.7 & 25.6 \\
\hline 2015 [37] & $\begin{array}{l}2010- \\
2012\end{array}$ & Korea & 22540 & 24100 & 16.16 & 22.4 & 11.5 \\
\hline 2018 [38] & 2013 & Mexico & 9960 & 10400 & 41.1 & 45.3 & 35 \\
\hline 2016 [39] & 2014 & Mexico & 10180 & 10600 & 70.4 & 74.8 & 63.7 \\
\hline 2017 [40] & 2016 & $\begin{array}{c}\text { Saudi } \\
\text { Arabia }\end{array}$ & 21730 & 20000 & 32.1 & 40.6 & 22.9 \\
\hline 2009 [41] & $\begin{array}{l}2004- \\
2006\end{array}$ & Singapore & 28370 & 29800 & 6.5 & 4.9 & 8.2 \\
\hline 2015 [42] & 2010 & Singapore & 44790 & 46500 & 12.3 & 14.8 & 9 \\
\hline 2009 [43] & 2005 & Spain & 25930 & 26500 & 18.4 & 21.8 & 12.5 \\
\hline 2012 [44] & NA & Thailand & 4140 & 4210 & 14.2 & 16.6 & 10.6 \\
\hline 2017 [45] & 2013 & UK & 42340 & 42700 & 15.5 & NA & NA \\
\hline 2014 [46] & 2012 & UK & 41200 & 41800 & 9.6 & 9.6 & 1 \\
\hline 2014 [47] & $\begin{array}{l}2005- \\
2008\end{array}$ & USA & 48640 & 48000 & 14.5 & 17.9 & 10.5 \\
\hline 2017 [48] & 2013 & USA & 53650 & 52800 & 6.8 & 8.4 & 5.3 \\
\hline 2009 [49] & 2004 & USA & 43680 & 41900 & 4.3 & 1 & 4.3 \\
\hline
\end{tabular}

NA: not applicable.

Table 2. Pooled prevalence of DED. 


\begin{tabular}{lcc}
\hline & No. of studies & Prevalence (\%) \\
\hline Total & 29 & 14.6 \\
Gender & & \\
Male & 26 & 11.5 \\
Female & 26 & 16.8 \\
Continent & & \\
Asia & 16 & 27.1 \\
Europe & 6 & 16.4 \\
Africa & 1 & 44.3 \\
South America & 1 & 12.8 \\
North America & 5 & 7.4 \\
WHO region & & \\
AFRO & 1 & 44.3 \\
AMRO & 6 & 7.6 \\
EMRO & 3 & 36.0 \\
EURO & 5 & 16.2 \\
SEARO & 2 & 31.3 \\
WPRO & 12 & 24.2 \\
Income category & & \\
HIC & 16 & 16.0 \\
UMIC & 6 & 26.4 \\
LMIC & 7 & 38.6 \\
\hline
\end{tabular}

Figures

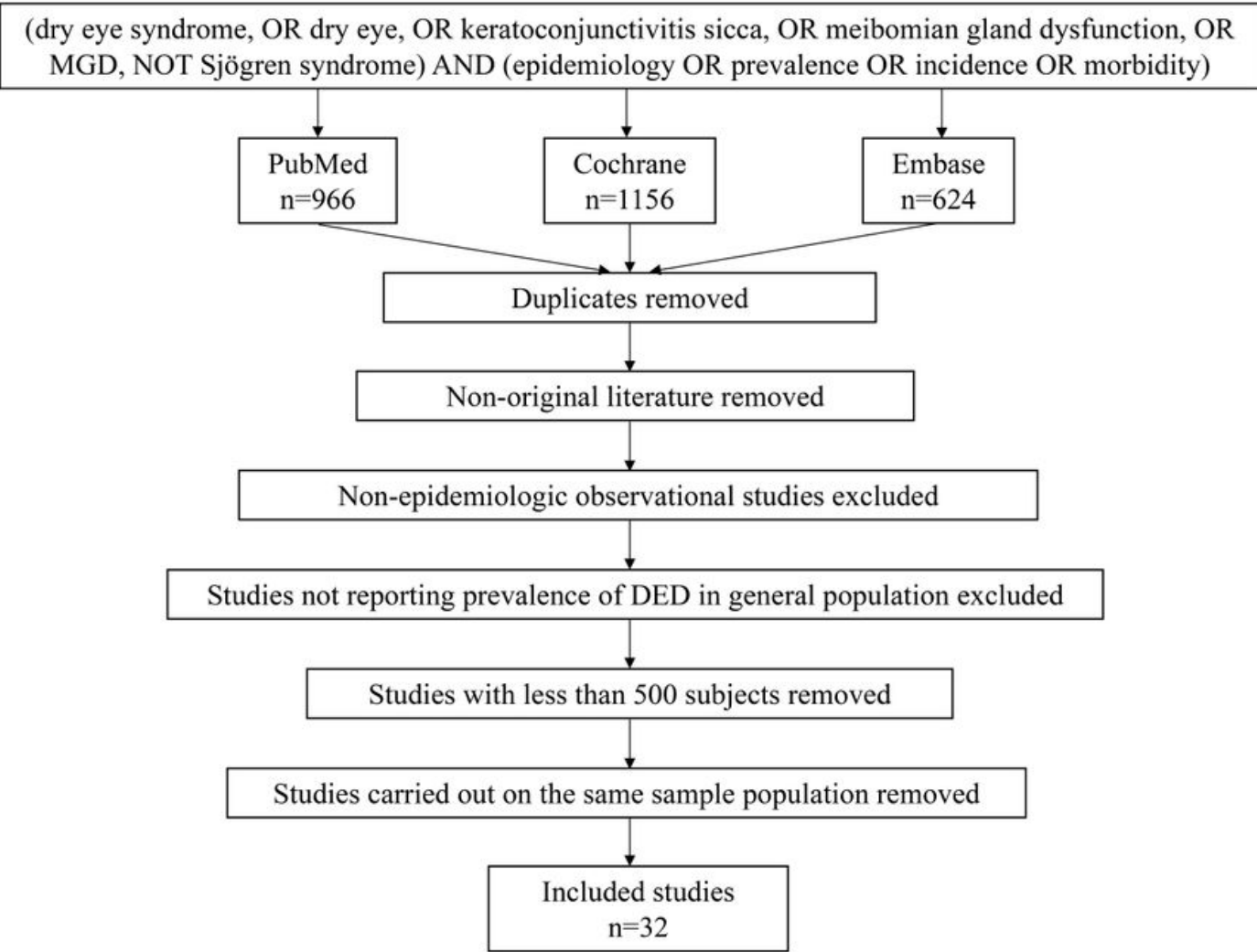

Figure 1 
Flowchart of the study evaluation process.

A.

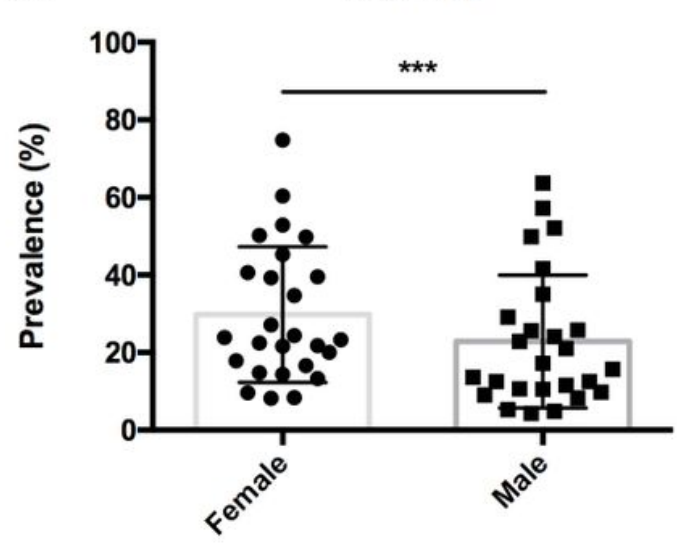

C.

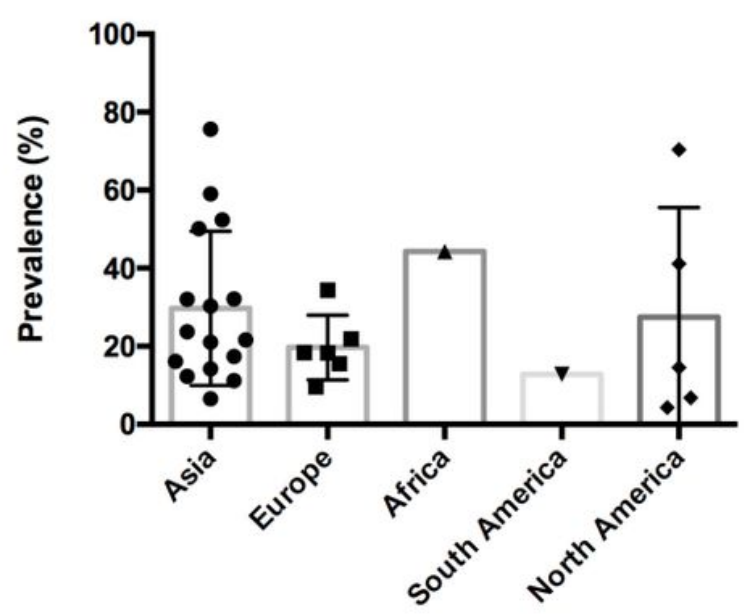

B.

WHO region

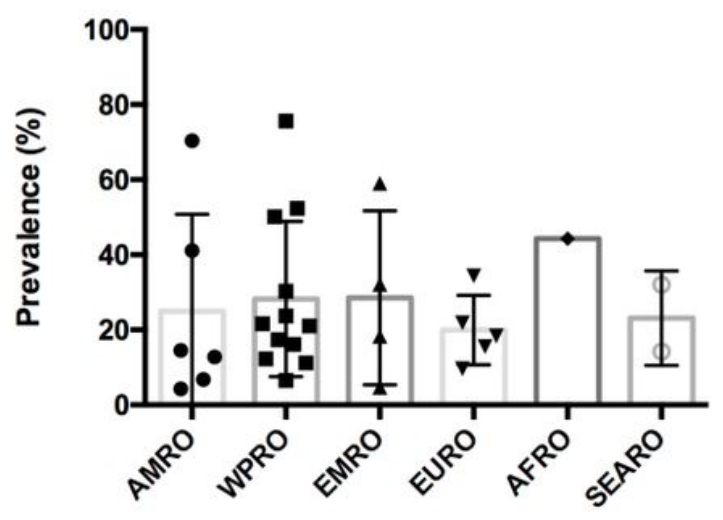

D.

Income

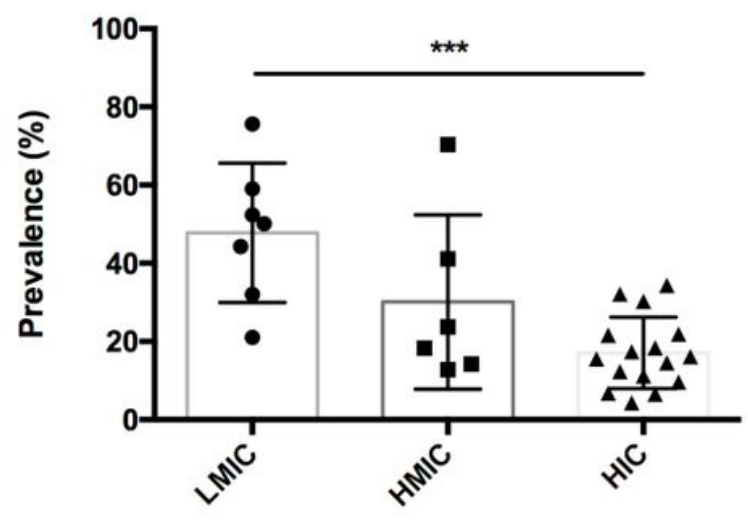

Figure 2

Comparisons of the prevalence of DED according to (A) gender, (B) WHO regions, (C) continents, and (D) income grouped by World Bank Income classifications.

A.

$y=-0.0006 x+41.527$

$\mathrm{R}^{2}=0.36396$

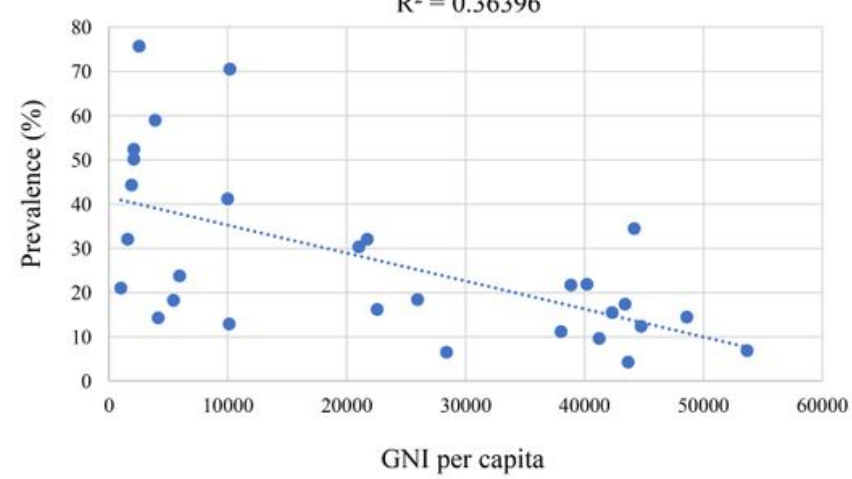

B. $y=-0.0006 x+41.365$

$\mathrm{R}^{2}=0.35969$

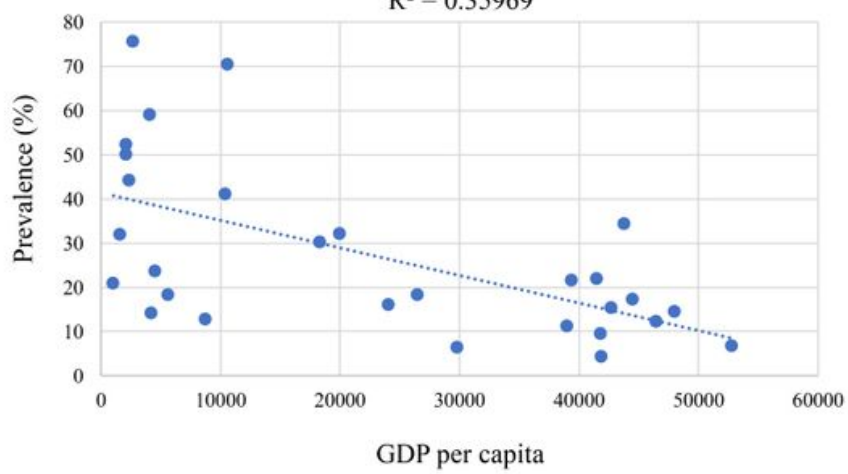


Figure 3

Scatterplots and correlations between the prevalence and (A) GNI per capita/ (B) GDP per capita.

\section{Supplementary Files}

This is a list of supplementary files associated with this preprint. Click to download.

- SupplementaryTable.docx 